\title{
Expression of Pancreatitis-Associated Protein after Traumatic Brain Injury: A Mechanism Potentially Contributing to Neuroprotection in Human Brain
}

\author{
Pia März-Weiss • Dieter Kunz • Daniel Bimmler • Caroline Berkemeier • \\ Suat Özbek • Beatrice Dimitriades-Schmutz • Johannes Haybaeck • \\ Uwe Otten · Rolf Graf
}

Received: 10 March 2011/Accepted: 20 May 2011/Published online: 5 June 2011

(C) Springer Science+Business Media, LLC 2011

\begin{abstract}
Neuronal cell death after severe traumatic brain injury (TBI) is caused by a complex interplay of pathological mechanisms including excitotoxicity, oxidative stress, mitochondrial dysfunction, extensive neuroinflammation, and ischemia-reperfusion injury. Pancreatitis-associated protein I (PAP I/reg2) was reported to be a survival factor for peripheral neurons, particularly sensory and motor neurons. In rat brains, by experimental TBI as well as by kainic acid induced brain seizure, PAP I and PAP III were found to be up-regulated in central neurons. In this study, we performed immunohistochemical staining in postmortem human brain from patients who died after severe TBI to demonstrate PAP expression on protein level in cerebellar Purkinje cells, pyramidal and granular neurons in cerebral cortex, and cortical neurons in the fore- and mid-brain. In primary cultures of rat brain cortical, hippocampal, and cerebellar
\end{abstract}

Pia März-Weiss and Dieter Kunz contributed equally in this study.

Electronic supplementary material The online version of this article (doi:10.1007/s10571-011-9715-0) contains supplementary material, which is available to authorized users.

\section{P. März-Weiss}

Translational Research, Hoffmann-LaRoche Ltd,

Grenzacherstrasse, 4070 Basel, Switzerland

D. Bimmler · R. Graf

Pancreatitis Research Laboratory, Department of Surgery,

University Hospital Zürich, 8091 Zürich, Switzerland

D. Kunz $(\bowtie) \cdot$ C. Berkemeier · B. Dimitriades-Schmutz •

U. Otten $(\triangle)$

Institute of Physiology, University of Basel,

Pestalozzistr. 20, 4056 Basel, Switzerland

e-mail: dieter.kunz@unibas.ch

U. Otten

e-mail: uwe.otten@unibas.ch neurons, we found neuroprotective effects for PAP I on $\mathrm{H}_{2} \mathrm{O}_{2}$-induced oxidative stress. Moreover, serum $\mathrm{K}^{+}$-deprivation induces apoptotic cell death in 55\% of cerebellar granule neurons (CGN), whereas upon treatment with PAP I only $32 \%$ of CGN are apoptotic. Using Western blot analyses, we compared protein phosphorylation in neuronal signaling pathways activated by PAP I versus Interleukin-6 (IL-6). We found a rapid activation of Akt-kinase phosphorylation by PAP I with a peak at $15 \mathrm{~min}$, whereas IL-6 induces Akt-phosphorylation lasting longer than $30 \mathrm{~min}$. Phosphorylation of MAP-42/44 kinases is stimulated in a comparable fashion. Both, IL-6 and PAP I increase phosphorylation of $\mathrm{NF} \kappa \mathrm{B}$ for activation of gene transcription, whereas only IL-6 recruits STAT3 phosphorylation, indicating that STAT3 is not a target of PAP I transcription activation in brain neurons. Application of the Akt-inhibitor Wortmanin reveals only a partial inhibition of PAP I-dependent protection of CGN from $\mathrm{H}_{2} \mathrm{O}_{2}$-induced oxidative stress. Based on our findings, we suggest that PAP I is a long lasting neurotrophic signal for central neurons. The neuroprotective effects parallel those that have been

\section{S. Özbek}

Institute for Molecular Evolution and Genomics,

University of Heidelberg, Im Neuenheimer Feld 230,

69120 Heidelberg, Germany

\section{J. Haybaeck}

Institute of Neuropathology, University Hospital Zürich,

8091 Zürich, Switzerland

\author{
J. Haybaeck \\ Institute of Pathology, Medical University Graz, \\ Auenbruggerplatz 25, 8036 Graz, Austria
}


described for effects of PAP I in ciliary neurotrophic factor (CNTF)-mediated survival of sensory and motor neurons. PAP I may act in autocrine and/or paracrine fashion and thus may contribute to endogenous protective mechanisms relevant under harmful conditions like oxidative stress, brain injury, or neurodegeneration.

Keywords Apoptosis - Traumatic brain injury . PAP I/reg2 - Oxidative stress · Human brain .

Central neurons $\cdot$ Neuroprotective action

$\begin{array}{ll}\text { Abbreviations } \\ \text { AD } & \text { Alzheimer's disease } \\ \text { CNTF } & \text { Ciliary neurotrophic factor } \\ \text { DMEM } & \text { Dulbecco's modified Eagle's medium } \\ \text { FCS } & \text { Foetal calf serum } \\ \text { H-IL-6 } & \text { Hyper-Interleukin-6 } \\ \text { LIF } & \text { Leukemia inhibitory factor } \\ \text { MEM } & \text { Minimal essential medium } \\ \text { NB } & \text { Neurobasal medium } \\ \text { NGF } & \text { Nerve growth factor } \\ \text { PAP } & \text { Pancreatitis-associated protein } \\ \text { Reg } & \text { Regenerating gene } \\ \text { wtm } & \text { Wortmannin }\end{array}$

\section{Introduction}

The pathogenesis of traumatic brain injury (TBI) is characterized by an interplay between excitotoxicity, oxidative stress, mitochondrial dysfunction, edema due to breakdown of the blood-brain barrier, an extensive neuroinflammatory response, and apoptosis caused by ischemia-reperfusion injury (Maas et al. 2008; Mazzeo et al. 2009).

The PAP/regenerating gene (Reg) family comprises a group of related genes grouped into subclasses I-IV which code for lectin-like proteins crucially involved in the regulation and modulation of inflammatory processes (Drickamer and Dwek 1995; Zhang et al. 2003; Graf et al. 2006). Several reports demonstrate that Reg proteins have functional roles in the peripheral nervous system (PNS). Pancreatitis-associated protein I (PAP I) was found to be a survival factor for motor neurons by acting as Schwann cell mitogen which is constitutively expressed during development and may be transcriptionally regulated by cytokines of the Interleukin-6 (IL-6) family (Livesey et al. 1997). During motor neuron development, PAP I contributes via Akt/PI3 kinase activation to the signaling pathways by which ciliary neurotrophic factor (CNTF) supports neuronal survival (Nishimune et al. 2000). After sciatic nerve transection, PAP I expression is rapidly upregulated in sensory neurons suggesting a distinct role in the peripheral nerve injury response (Averill et al. 2002). Expression of PAP I and PAP II is strongly induced in dorsal root ganglion (DRG) neurons following peripheral tissue inflammation and nerve injury suggesting an important role in the modulation of spinal sensory pathways in chronic pain states (He et al. 2010). PAP III appears to have a specific role in peripheral nerve regeneration (Namikawa et al. 2005, 2006). Very recent reports from rat models of brain injury, particularly, in neuroinflammation associated with TBI (Ampo et al. 2009) as well as in kainic acid-induced brain seizure (Kawahara et al. 2011) demonstrate elevated PAP I and PAP III expression also in central neurons.

Until now, only few reports demonstrate increased PAP expression in human brain, particularly, in Alzheimer's disease (AD) brain and plaques derived from $\mathrm{AD}$ brain as well as in developing human brain (de la Monte et al. 1990; Duplan et al. 2001). The aim of this study was to investigate the potential neuroprotective effects of PAP and their underlying signal transduction pathways. Furthermore, we aimed to demonstrate the expression of PAP in neurons in brains of TBI patients and of rats.

\section{Experimental Procedures}

\section{Materials}

Neurobasal medium (NB), B-27 Supplement, L-glutamine, Minimal Essential Medium (MEM), trypsin, penicillin, and streptomycin were purchased from Invitrogen Gibco. Defined fetal calf serum (FCS) Gold was from PAA Laboratories, Pasching, Austria. Bovine serum albumin (BSA) was obtained from Sigma. Wortmannin (wtm) was purchased from Calbiochem.

\section{Cytokines and Antibodies}

The fusion protein Hyper-IL-6 (H-IL-6) was expressed in stably transfected $\mathrm{CHO}$ cells and purified to homogeneity as described (Fischer et al. 1997). Rat recombinant PAP I was expressed in Pichia pastoris and purified as described (Schiesser et al. 2001). Anti-human PAP and PAP antibodies were generated as described ( $\mathrm{Li}$ et al. 2009). Polyclonal antibodies raised against phospho-Ser ${ }^{473} \mathrm{Akt}$, phospho-Thr ${ }^{202} / \mathrm{Tyr}^{204} \mathrm{p} 44 / \mathrm{p} 42-\mathrm{MAP}$ kinases, phospho$\mathrm{Ser}^{536} \mathrm{NF} \kappa \mathrm{B}$ p65, and phospho-Tyr ${ }^{705}$ STAT3 were from Cell Signaling Technology. Monoclonal anti-beta-actin antibody was from Sigma. Polyclonal anti rat PAP I antibody was raised in rabbits against the recombinant protein as described (Schiesser et al. 2001). 
Primary Neuronal Cell Cultures

All media for culture and handling of neuronal cells were adjusted to High-potassium (HK) media by addition of $\mathrm{KCl}$ to a final $\mathrm{K}^{+}$-concentration of $25 \mathrm{mM}$ from the standard $5.4 \mathrm{mM}$ present within the media. Primary neurons from different brain regions were prepared from newborn Wistar rats (postnatal day 1) as described (Brewer et al. 1993) with minor modifications. Hippocampi, cerebella, and cortices were dissected and meninges removed. Tissues were first slightly triturated with a sterile Pasteur pipette followed by trituration with a fire-polished Pasteur pipette (opening reduced to $50-70 \%$ of its normal diameter) until no visible aggregates of tissue remained. After 2-3 min tissue segments, larger debris settled down, and supernatants containing single cells were transferred to fresh tubes. The trituration procedure was repeated until no visible aggregates of tissue remained. Single cell suspensions were centrifuged at $200 \times g$ for $5 \mathrm{~min}$, and cell pellets were resuspended in HK-NB supplemented with $0.5 \mathrm{mM}$ L-glutamine and $1 \%$ penicillin-streptomycin sulfate. After counting, cells were diluted with specific culture media, seeded at a density of $6 \times 10^{5}$ cells $/ \mathrm{cm}^{2}$ into polyD-lysine-coated 96-well or 24-well plates (Beckton \& Dickinson) and cultured at $37^{\circ} \mathrm{C}$ in an atmosphere of $5 \%$ $\mathrm{CO}_{2}$ and $100 \%$ humidity. Specific media for cerebellar and cortical neurons were HK-MEM supplemented with glucose (final $25 \mathrm{mM}$ ), $0.5 \mathrm{mM}$ L-glutamine, $0.23 \mathrm{mM}$ Na-Pyruvate, $1 \%$ penicillin-streptomycin sulfate, and 5\% FCS. Hippocampal cells were grown in HK-NB with $1 \%$ B-27 supplement, $0.5 \mathrm{mM}$ L-glutamine, and 5\% FCS. For growth arrest of non-neuronal cells, $10 \mu \mathrm{M}$ cytosine arabinofuranoside (Sigma) was added to cultures 3 days after seeding. Every 3 days in culture, one-half of the medium was removed and replaced by fresh serum-free HK medium to adjust to the original volume. After 7 days in culture (DIV7), cells consisted of almost 99\% neurons and were used for the experiments.

\section{$\mathrm{H}_{2} \mathrm{O}_{2}$-Induced Oxidative Stress and $\mathrm{K}^{+}$-Deprivation}

Oxidative stress was induced by administration of 50-150 $\mu \mathrm{M} \mathrm{H}_{2} \mathrm{O}_{2}$ for $24 \mathrm{~h}$ in serum-free HK-NB. Afterward, $\mathrm{H}_{2} \mathrm{O}_{2}$ was washed out, and cells were incubated in HK-NB media for further $24 \mathrm{~h}$ followed by determination of neurotoxicity. Recombinant PAP I was added simultaneously with the toxic stimulus and added again after $\mathrm{H}_{2} \mathrm{O}_{2}$ removal for another $24 \mathrm{~h}$. For $\mathrm{K}^{+}$-deprivation, cells were cultured for $24 \mathrm{~h}$ in freshly added serum-free Low-potassium medium (LK; NB with 2\% B-27 supplement, $0.5 \mathrm{mM}$ L-glutamine, $5.4 \mathrm{mM} \mathrm{K}^{+}$final, and $1 \%$ penicillin-streptomycin sulfate) containing vehicle or recombinant PAP I at $200 \mathrm{ng} / \mathrm{ml}$.
Cell Viability Assays

Cell viability was either determined by measuring lactate dehydrogenase (LDH) release into the cell culture media or quantitated by counting the number of dead cells using DAPI or TUNNEL assay. Neurotoxicity upon oxidative stress was measured by release of LDH from the cytosol of damaged cells into the supernatant as described by the manufacturer (Roche Diagnostics). Concentrations of $\mathrm{H}_{2} \mathrm{O}_{2}$ needed to induce half-maximal toxicity was routinely determined in independent experiments using sister cultures. For measurement of apoptosis after $\mathrm{K}^{+}$-deprivation, cells were treated for DAPI staining as described by the manufacturer (Roche Diagnostics). Cells were stained with $1 \mu \mathrm{g} / \mathrm{ml}$ DAPI in Methanol for $15 \mathrm{~min}$ at $37^{\circ} \mathrm{C}$. After washing with Methanol, cells were covered with PBS, and the ratio of condensed versus intact nuclei was quantitated in a fluorescence microscope. A TUNEL assay was performed using Roche apoptosis detection kit according to the manufacturer's instructions (Roche Diagnostics). After fixation, labeling (50 $\mu 1$ TUNEL reaction mixture consisting of $45 \mu 1$ TUNEL label plus $5 \mu 1$ TUNEL enzyme) and PBS wash, the number of apoptotic cells was counted in a fluorescence microscope.

\section{Immunohistochemical Staining of PAP}

Sections of human brains were prepared following autopsy. Conventional formalin fixation and paraffin embedding followed. Antigen retrieval was performed by boiling sections in a microwave oven, followed by blocking and exposure to the human PAP antibodies as described previously (Graf et al. 2002).

\section{PAP I ELISA}

Rat PAP I was measured using an isoform-specific ELISA as described (Graf et al. 2002).

\section{Western Blot Analysis}

Primary cerebellar neurons were washed with NB once and incubated in NB for $3 \mathrm{~h}$ to reduce basal activation. Afterward, neurons were stimulated with vehicle (control), H-IL-6, or PAP I. After 0, 15, and 30 min, the medium was removed, and cells were lyzed in $2 \times$ Laemmli buffer. Proteins were separated by SDS-PAGE and blotted onto PVDF membranes. Membranes were blocked for $1 \mathrm{~h}$ in phosphate-buffered saline with 5\% BSA and $0.1 \%$ Tween 20 at RT and incubated with primary activation-specific antibodies (1:1000) against PAP I, phospho-Ser ${ }^{473}$ Akt, phospho- $\mathrm{Thr}^{202} / \mathrm{Tyr}^{204}$ p44/p42-MAP kinases, phospho-Ser ${ }^{536}$ $\mathrm{NF} \kappa \mathrm{B}$ p65, and phospho-Tyr ${ }^{705}$ STAT3 overnight at $4{ }^{\circ} \mathrm{C}$ 
followed by horseradish peroxidase-conjugated goat anti rabbit antibody (1:4000, Sigma). The blots were developed using the ECL-detection system (Amersham). After ECL detection, the membrane was rehydrated in phosphatebuffered saline and incubated with an anti-beta-actin antibody (1:5000; Sigma) as an internal loading control.

\section{Human Brain Tissue Samples and Subjects}

This study was approved by the human subjects committees of Kantonale Ethikkommission Zurich.

We collected brains at autopsy from 4 patients who died 7-42 (mean 19) days after severe TBI. Causes of death were multiorgan failure $(n=2)$, elevated intracranial pressure $(n=1)$, and brain death $(n=1)$. We obtained four additional brains from control subjects with no clinical evidence of TBI or other neurological disorders. Those subjects died from ruptured aortic aneurysm $(n=1)$, liver failure $(n=1)$, drowning $(n=1)$, and myocardial infarction $(n=1)$. First-degree relatives gave written informed consent for autopsy and tissue research.

\section{Results}

Immunohistochemical Staining of PAP in Human Brain

Immunohistochemical staining of different brain areas consistently revealed that only neurons express PAP at various levels while other cell types were negative for PAP staining (Fig. 1). Sections treated with pre-immune serum were always negative. The cerebellar cortex showed PAPpositive Purkinje neurons only in some cases whereas the granular cell layer as well as the molecular layer consistently lacked any immune reactivity. Pyramidal and granular neurons of the cerebral cortex displayed a similar behavior as seen in Purkinje cells while again astrocytes and oligodendrocytes were completely negative. Cortical neurons were also positive in the fore- and mid-brain.

In parallel experiments, we used isolated primary cultures of rat brain neurons, astrocytes, and microglial cells to monitor PAP I expression using a specific PAP I ELISA. As shown in Supplementary Figure S1, only neurons displayed PAP I expression. Among the cytokines of the IL-6 family known to regulate PAP I expression, CNTF is the strongest inducer. However, trans-signaling of H-IL-6, in which IL-6 is covalently linked to its soluble receptor sIL-6R, turns out to be an extraordinary strong inducer of PAP I expression, generating high levels of long lasting PAP I protein even when PAP I gene transcription is already declined (Supplementary Figure S2).

PAP I Mediates Protection of Brain Neurons against $\mathrm{H}_{2} \mathrm{O}_{2}$-Induced Neurotoxicity and Apoptosis Induced by Serum $\mathrm{K}^{+}$-Deprivation

We next examined whether PAP I would have protective effects and may rescue brain neurons from cellular damage due to oxidative stress and apoptosis, two key features of TBI pathogenesis. The results shown in Fig. 2a revealed

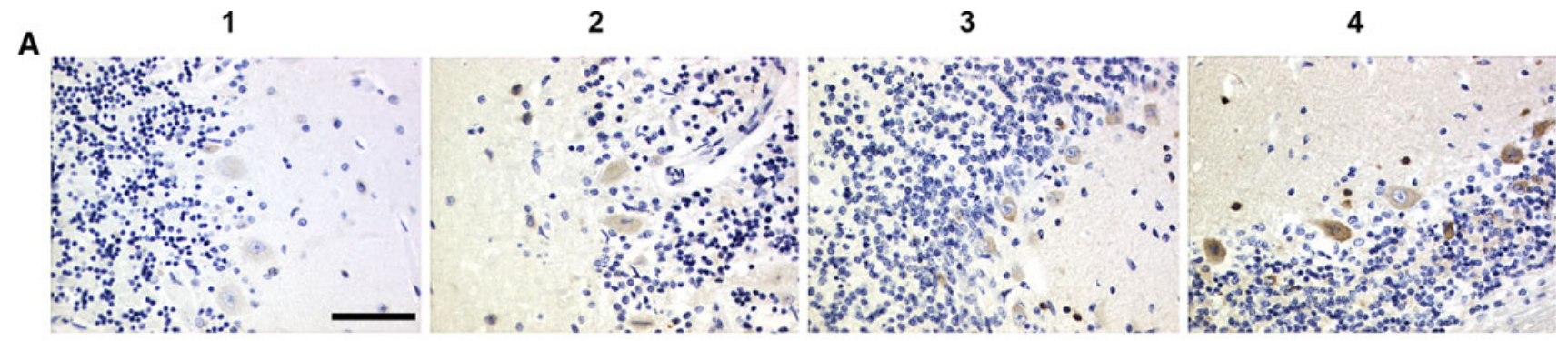

B

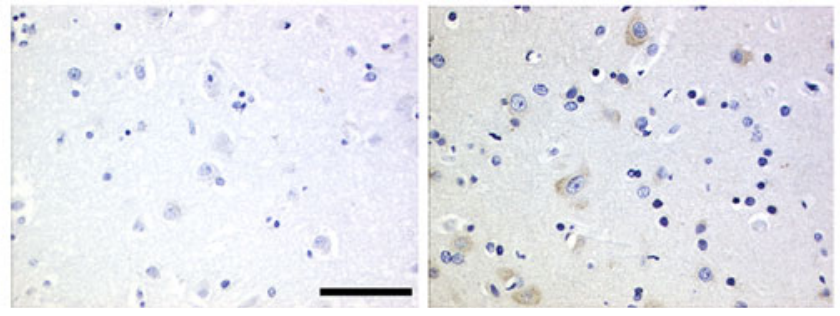

Fig. 1 Immunohistochemical staining for PAP in human brain. a Cerebellar cortex with granular cell layer, Purkinje neurons and molecular layer is shown. Immunohistochemistry with control serum $(\mathbf{a} 1, \mathbf{b} 1)$ or PAP-specific antiserum $(\mathbf{a} 2-\mathbf{a} 4, \mathbf{b} 2-\mathbf{b} 4)$. a2-a4: Purkinje cells either stain completely negative (a2), weakly positive (a3), or

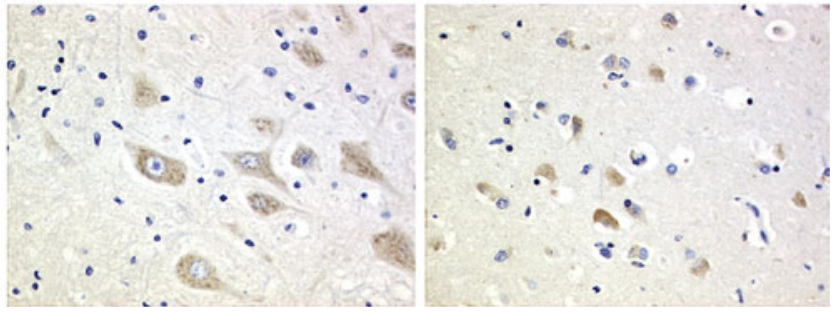

moderately positive (a4) for PAP. b Control (b1), b2-b4: Cortical neurons either stain completely negative (b2), weakly positive (b3), or moderately positive (b4). Astrocytes and oligodendrocytes are consistently negative; scale bars: $150 \mu \mathrm{m}$ 
that maximal neurotoxicity in CGN was obtained with $200 \mu \mathrm{M} \mathrm{H} \mathrm{H}_{2} \mathrm{O}_{2}$ with half-maximum at about $75 \mu \mathrm{M}$ $\mathrm{H}_{2} \mathrm{O}_{2}$. Addition of recombinant PAP I protected CGN from $\mathrm{H}_{2} \mathrm{O}_{2}$-induced neurotoxicity in a dose-dependent manner (Fig. 2b, c). In addition, hippocampal and cortical neurons were dose-dependently protected by PAP I against oxidative stress-induced neurotoxicity (Fig. 2c). The highest PAP I concentration at $200 \mathrm{ng} / \mathrm{ml}$ revealed neuroprotection up to $60 \%$. Apoptosis in CGN was induced by serum $\mathrm{K}^{+}$-deprivation, and the degree of neuronal apoptosis was assessed using TUNEL assay and DAPI staining. As shown in Fig. 3, about $55 \%$ of neurons in LK medium are apoptotic whereas treatment with PAP I reduces the number of apoptotic cells to about $32 \%$.
PAP I Versus IL-6-Induced Activation of Signaling Pathways in Brain Neurons

Using Western blot analyses from CGN lysates, we examined by which signaling pathways brain neurons might respond to PAP I as compared to the neuropoietic cytokine IL-6. As shown in Fig. 4a, a transient phosphorylation of Akt-kinase was rapidly induced by PAP I with a peak $15 \mathrm{~min}$, whereas IL-6 appears to induce Akt-phosphorylation lasting longer than $30 \mathrm{~min}$. Phosphorylation of MAP-42/44 kinases is stimulated in comparable fashion, however, with different intensities (Fig. 4a). For activation of gene transcription, both IL-6 and PAP I increase phosphorylation of NF $\kappa$ B (Fig. 4b), Only IL-6 recruits STAT3
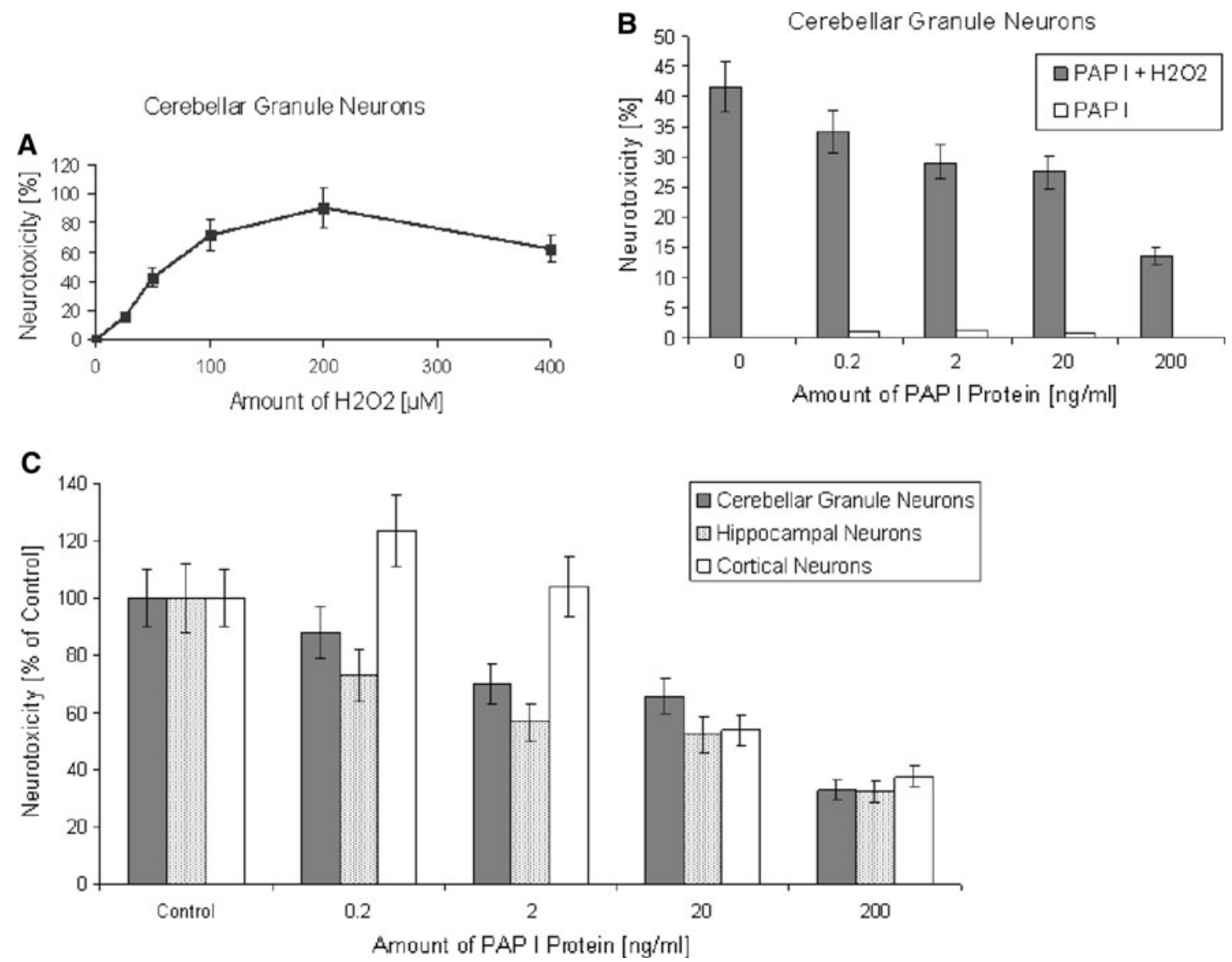

Fig. 2 PAP I-mediated protection of Rat brain neurons from $\mathrm{H}_{2} \mathrm{O}_{2}$ induced neurotoxicity. a Cultured primary CGNs were treated with 0 , $25,50,100,200$, and $400 \mu \mathrm{M}$ of $\mathrm{H}_{2} \mathrm{O}_{2}$ for $1 \mathrm{~h}$. Culture medium was changed and cells incubated for further $24 \mathrm{~h}$. Thereafter, neurotoxicity was measured as LDH release into the culture medium. Values are expressed as means \pm SEM from three independently performed experiments. b Two series of cultured primary CGN were treated with PAP I protein at concentrations of 0 (Control), 0.2, 2, 20, and $200 \mathrm{ng} /$ $\mathrm{ml}$ culture medium for $24 \mathrm{~h}$. Thereafter, culture media were changed. One series was treated with $75 \mu \mathrm{M} \mathrm{H}_{2} \mathrm{O}_{2}$ for $1 \mathrm{~h}$; the other series left untreated. Then, cell culture media were changed and cells incubated for further $24 \mathrm{~h}$. Neurotoxicity in all cultures was measured as LDH release into the culture medium. Values are expressed as mean$\mathrm{s} \pm \mathrm{SEM}$ from three independently performed experiments. $\mathrm{c} \mathrm{Cul-}$ tured primary hippocampal and cortical neurons were treated as described above, except that oxidative stress was induced using $150 \mu \mathrm{M} \mathrm{H}_{2} \mathrm{O}_{2}$ for $1 \mathrm{~h}$. Neurotoxicity was monitored as LDH release into the culture medium. Values of LDH release for Control were set to $100 \%$, and all other values were normalized accordingly. Values are expressed as means \pm SEM from three independently performed experiments 


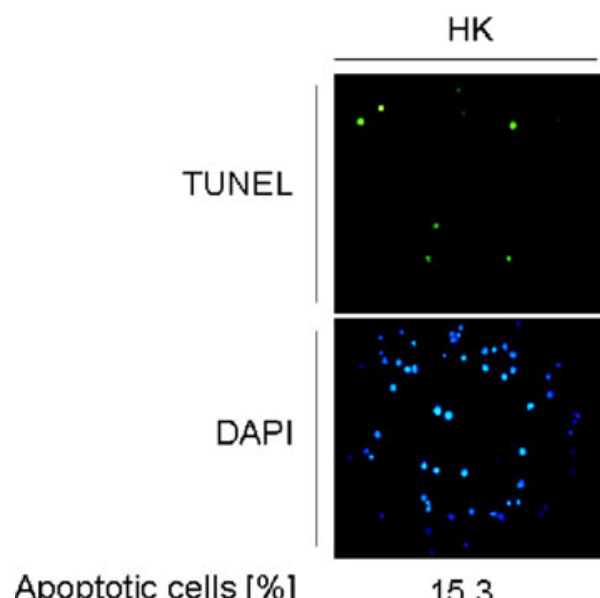

Apoptotic cells [\%]

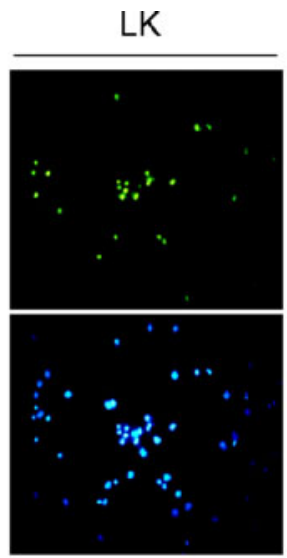

55.0

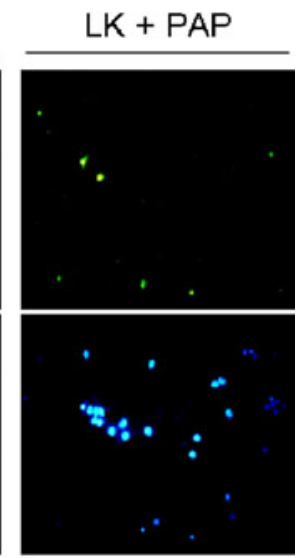

32.4
Fig. 3 PAP I-mediated protection of Rat brain neurons from apoptosis induced by serum $\mathrm{K}^{+}$-deprivation. For induction of neuronal apoptosis, CGNs were cultured for $24 \mathrm{~h}$ in serum-free HK medium (HK), LK medium (LK), or LK medium containing $200 \mathrm{ng} / \mathrm{ml}$ of PAP I
(LK + PAP I) and subsequently stained using TUNNEL assay and DAPI to assess the degree of neuronal apoptosis. About $55 \%$ of neurons in LK medium are apoptotic whereas treatment with PAP I reduces the number of apoptotic cells to about $35 \%$
Fig. 4 PAP I-induced signaling mechanisms in brain neurons. Cultured primary CGNs were unstimulated (Control) or stimulated for 5,15 , and $30 \mathrm{~min}$ either with PAP I $(200 \mathrm{ng} / \mathrm{ml})$ or H-IL-6 (20 ng/ml), respectively. Treatment with H-IL-6 served as positive control. Cell lysates were subjected to SDS-PAGE and Western blot analysis using antibodies raised against phospho-Ser ${ }^{473}$ Akt (a), phospho-Thr ${ }^{202} / \mathrm{Tyr}^{204} \mathrm{p} 44 /$ p42-MAP kinases (a), phospho$\mathrm{Ser}^{536} \mathrm{NF} \kappa \mathrm{B}$ p65 (b), and phospho-Tyr ${ }^{705}$ STAT3 (c) as $^{-1}$ compared to $B$-actin. One representative result from two individually performed experiments is displayed
A

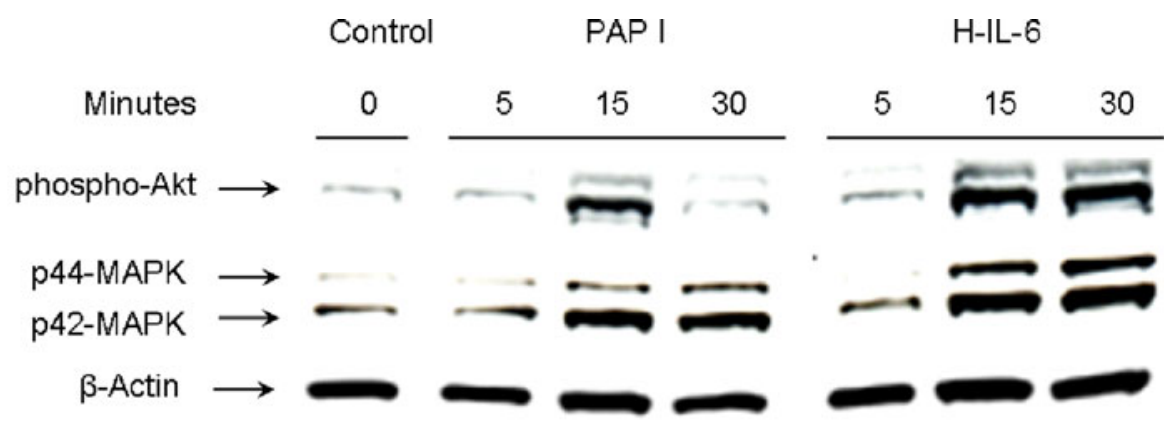

B

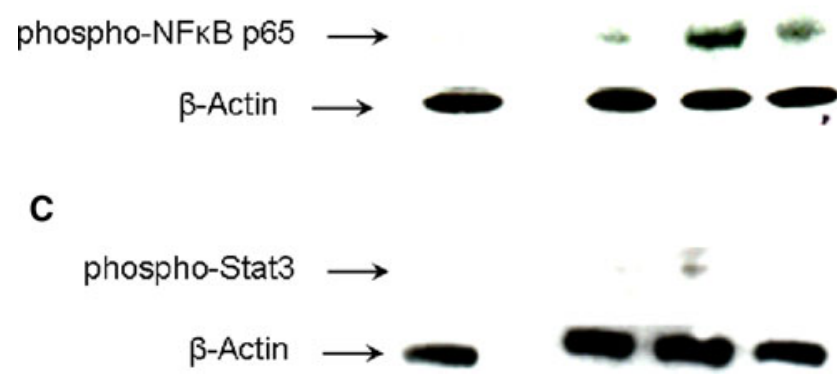

by protein phosphorylation (Fig. 4c), indicating that STAT3 is not a target of PAP I in brain neurons.

The Akt/PI3 Kinase Pathway only Partially Contributes to PAP I-Mediated Neuroprotection

In light of the transient phosphorylation of Akt-kinase by PAP I in central neurons, we investigated the contribution of the Akt/PI3-pathway to the neuroprotective effects of PAP I on $\mathrm{H}_{2} \mathrm{O}_{2}$-induced neuronal damage or whether there might be other mechanisms that would operate in PAP I-induced neuroprotection as well. Using the specific Akt activation inhibitor wtm at $20 \mathrm{nM}\left(\mathrm{IC}_{50}\right.$ about $\left.5 \mathrm{nM}\right)$, our experiments revealed that only part of the PAP I-mediated neuroprotective effect can be attributed to the Akt signaling pathway (Fig. 5). This indicates that PAP I-specific neuroprotection is not confined to a single survival pathway but that additional signaling cascades are involved.

\section{Discussion}

In this study, we demonstrate expression of PAP in postmortem brain from patients who died from severe TBI. 


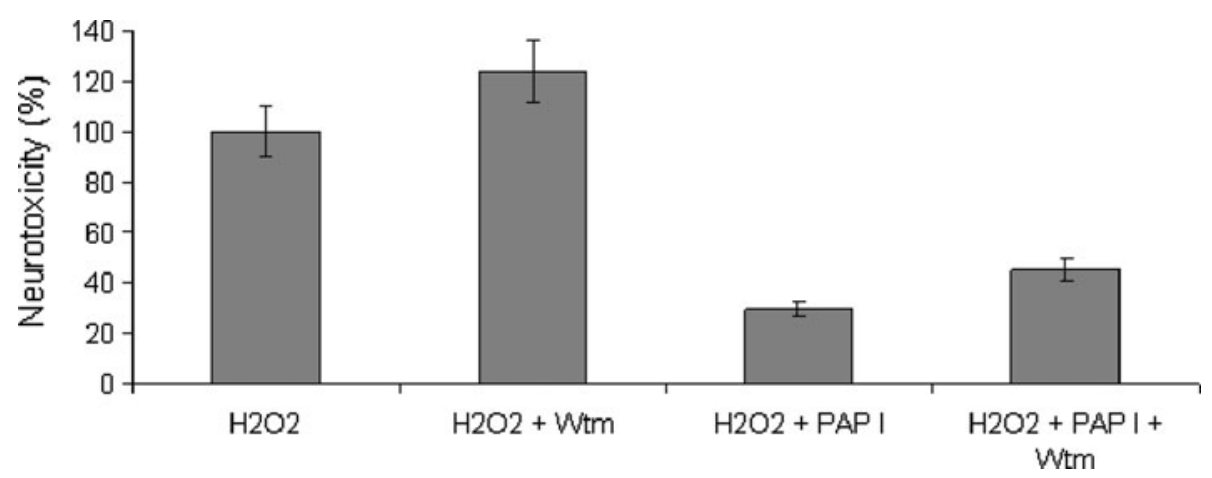

Fig. 5 Effect of Akt signaling inhibition on PAP I-mediated neuroprotection. Cultured CGNs were treated with $\mathrm{H}_{2} \mathrm{O}_{2}(75 \mu \mathrm{M}), \mathrm{H}_{2} \mathrm{O}_{2}$ $(75 \mu \mathrm{M})$ plus wortmannin (wtm; $20 \mathrm{nM} ; \mathrm{IC}_{50}$ at about $5 \mathrm{nM}$ ), $\mathrm{H}_{2} \mathrm{O}_{2}$ $(75 \mu \mathrm{M})$ plus PAP I $(200 \mathrm{ng} / \mathrm{ml})$ or $\mathrm{H}_{2} \mathrm{O}_{2}(75 \mu \mathrm{M})$ plus PAP I

In accordance to studies in animal models of brain injury (Ampo et al. 2009; Kawahara et al. 2011), only neurons are found to express PAP. Ampo and coworkers induced TBI by weight drop in rat brains and, using immunohistochemical double-staining analyses, showed that PAP I- and PAP-III protein expression was localized in a subpopulation of neurons within the peri-injured region. PAP I induction reached maximum levels at day $1-3$ followed by a decline to day 7 post TBI. Moreover, transient up-regulation of cytokine mRNAs coding for TNF- $\alpha$ with a peak at $1 \mathrm{~h}$, for IL- $1 \beta$ and IL- 6 with peak levels at $4 \mathrm{~h}$ after TBI were found. Whereas TNF- $\alpha$ mRNA levels remain elevated up to 7 days, those for IL- $1 \beta$ and IL- 6 are clearly terminated or return to a baseline at 1 day post TBI (Ampo et al. 2009). These in vivo data and the results on PAP I expression in H-IL-6-stimulated PC 12 cells provided in our Figure S2 clearly demonstrate a high level, long lasting expression of PAP I even when cytokine-induced gene transcription is already declined.

Moreover, our data in Figure S1 show that PAP I expression in CGN by IL-6 alone is less efficient as compared to the designer cytokine H-IL-6 in which IL-6 is covalently linked to its soluble receptor sIL-6R (Fischer et al. 1997). This indicates a major contribution of the process of trans-signaling to neuronal PAP I expression. IL-6 is a member of the family of gp130 cytokines which exert signal transduction by binding to the cellular gp130 transducing component either via a plasma-membranebound receptor IL-6R or by a soluble IL-6 receptor sIL-6R. The principle of trans-signaling via sIL-6R enlarges the spectrum of IL-6 target cells, among them rat sympathetic and DRG neurons (Jones et al. 2005; Rose-John et al. 2007). From previous studies in our laboratory, it is known that rat sympathetic neurons contain only a marginal number of membrane-bound IL-6 receptors and strongly respond to IL-6 via trans-signaling (März et al. 1998, 1999). In vivo, plasma levels of sIL-6R in healthy
(200 ng/ml) plus wtm $(20 \mathrm{nM})$ for $1 \mathrm{~h}$. Wtm was applied $30 \mathrm{~min}$ before addition of PAP I. Neurotoxicity was measured as LDH release into the culture medium. Values are expressed as means \pm SEM from three independently performed experiments

individuals were found to be in the range of about $25-35 \mathrm{ng} / \mathrm{ml}$ and elevated levels associated with numerous inflammatory disease states such as Crohn's disease, rheumatoid arthritis (RA), juvenile RA, and osteoarthritis (Rose-John et al. 2007). However, so far nothing is known about the levels of sIL-6R in injured organ tissues such as TBI brain. Thus, it would be interesting to investigate sIL-6R levels in TBI brain as it may be speculated that in a neuroinflammatory state as in the TBI brain, high levels of sIL-6R may be generated to support the protective actions of the cytokine and its secondary factors such as PAP.

Recently, we reported gene chip analyses in which we monitored the gene sets recruited by H-IL-6 as compared to Nerve growth factor (NGF) in PC12 cells as a valid model for neuronal differentiation and survival (Kunz et al. 2009). We found that H-IL-6 actions include up-regulation of 'secondary' signals such as growth factors and other functionally related extracellular proteins including several members of the Reg/PAP family, in particular, regenerating islet-derived 3 alpha (REG3A), PAP I, REG1A/Pancreatic stone protein (PSP), and REG3G/PAP II (Kunz et al. 2009). These factors may synergize with IL-6 and other cytokines and/or may take over further autocrine and paracrine tasks to control short-and long-term effects as part of a local microenvironment suitable to improve neuronal growth, differentiation, and survival in an injured brain region.

An important cellular target of IL-6 actions in the brain is the oligodendrocyte. IL-6 as well as H-IL-6 have been shown to enhance survival and differentiation of oligodendrocyte precursor cells (Valerio et al. 2002) and to prevent neuron as well as oligodendrocyte degeneration following excitotoxic injury (Pizzi et al. 2004). Moreover, H-IL-6 was found to act as a stimulator of myelination of embryonic stem cell-derived oligodendrocytes (Zhang et al. 2006). These observations are in line with peripheral myelin producing Schwann cells, known to respond to PAP 
I and to promote nerve regeneration (Livesey et al. 1997). An interesting question is whether IL-6-mediated effects on oligodendrocyte viability are either caused by direct IL-6 actions on the oligodendrocyte or indirectly via neuronal PAP I expression.

Among others, neurodegenerative mechanisms following TBI may include cellular damage due to oxidative stress and apoptosis. The results obtained herein on the protection from $\mathrm{H}_{2} \mathrm{O}_{2}$-induced oxidative stress as well as $\mathrm{K}^{+}$-deprivation induced apoptosis strongly suggest that PAP I-induced neuroprotection is a common phenomenon to neuronal subpopulations of different brain regions. In order to define the potential protective role of PAP I on central neurons, we have delineated the signaling mechanisms contributing to PAP I-mediated neuron-specific effects. PAP I leads to phosphorylation of Akt, p44/p42-MAP kinases as well as of $\mathrm{NF} \kappa \mathrm{B}$ indicating that similar mechanisms are used in brain as compared to the PNS. In contrast to the neuroprotective effect of PAP I on spinal motor neurons where inactivation of the PI3 kinase completely abolishes PAP I-mediated neuron survival, brain neurons appear to be only partially dependent on Akt/PI3 kinase signaling. These results indicate that in central neurons, multiple signaling pathways may converge and other signaling cascades seem to participate additionally in PAP I-mediated neuron survival. A marked upregulation of the IL-6 system following injury and neurodegeneration was observed on various brain regions (Gadient and Otten 1997). IL-6 protects hippocampal and cerebellar neurons against neurotoxicity (Sun et al. 2002; Peng et al. 2005), ischemic damage (Yamashita et al. 2005) as well as lesioninduced brain injury (Penkowa et al. 2003a, b; Cao et al. 2006). An interesting question is whether PAP contributes to all these neuroprotective effects.

Remarkably, PAP I and PSP have been reported to be increased in early stages of AD (Duplan et al. 2001). Recently, we have shown that members of the PAP/Reg protein family display highly aggregative properties under physiological conditions after trypsin cleavage at the ArgIle bond in position 11-12 (Graf et al. 2001). The generated C-terminal fragment is largely insoluble at physiological $\mathrm{pH}$ and readily polymerizes into organized fibrils; theses structures are highly reminiscent of fibrillar deposits found in brain tissues associated with diverse neurodegenerative diseases. Generation of cleaved, misfolded peptides which aggregate and accumulate often leads to neuronal dysfunction (Selkoe 2003; Soto 2003). However, it remains unclear whether brain-specific cleavage of PAP-related proteins occurs in intact brain and moreover whether these cleaved proteins are involved in neuroprotective or neurodegenerative processes.

In the study reported herein, we provide substantial evidence for a key role of PAP I to protect brain neurons against damaging stimuli. Additional studies are needed to prove whether PAP I is directly responsible for the neuroprotective effects of IL- 6 type cytokines in the brain or whether additional regulatory stimuli are needed to induce PAP I synthesis. Better understanding of the mechanisms involved in PAP I receptor-mediated intrinsic survival programs in brain neurons should help to develop novel therapeutic strategies for neuroprotection.

Acknowledgments This study was supported by Swiss National Foundation Grant 3100BO-100730 (to U.O.) and by Stiftungs-Förderstipendium of the University of Basel (to P.M.). Further support was received from the Amelie Waring Stiftung, Zurich (to R.G). We are grateful to S.P. Hunt for supply with Reg-2 antibody.

\section{References}

Ampo K, Suzuki A, Konishi H, Kiyama H (2009) Induction of pancreatitis-associated protein (PAP) family members in neurons after traumatic brain injury. J Neurotrauma 10:1683-1693

Averill S, Davis DR, Shortland PJ, Priestley JV, Hunt SP (2002) Dynamic pattern of reg-2 expression in rat sensory neurons after peripheral nerve injury. J Neurosci 22:7493-7501

Brewer GJ, Torricelli JR, Evege EK, Price PJ (1993) Optimized survival of hippocampal neurons in B27-supplemented Neurobasal, a new serum-free medium combination. J Neurosci Res 35:567-576

Cao Z, Gao Y, Bryson JB, Hou J, Chaudhry N, Siddiq M, Martinez J, Spencer T, Carmel J, Hart RB, Filbin MT (2006) The cytokine interleukin-6 is sufficient but not necessary to mimic the peripheral conditioning lesion effect on axonal growth. J Neurosci 26:5565-5573

de, la Monte SM, Ozturk M, Wands JR (1990) Enhanced expression of an exocrine pancreatic protein in Alzheimer's disease and the developing human brain. J Clin Invest 86:1004-1013

Drickamer K, Dwek RA (1995) Carbohydrates and glycoconjugates. Curr Opin Struct Biol 5:589-590

Duplan L, Michel B, Boucraut J, Barthellemy S, Desplat-Jego S, Marin V, Gambarelli D, Bernard D, Berthezene P, AlescioLautier B, Verdier JM (2001) Lithostathine and pancreatitisassociated protein are involved in the very early stages of Alzheimer's disease. Neurobiol Aging 22:79-88

Fischer M, Goldschmitt J, Peschel C, Brakenhoff JP, Kallen KJ, Wollmer A, Grotzinger J, Rose-John S (1997) A bioactive designer cytokine for human hematopoietic progenitor cell expansion. Nat Biotechnol 15:142-145

Gadient RA, Otten UH (1997) Interleukin-6 (IL-6)—a molecule with both beneficial and destructive potentials. Prog Neurobiol 52:379-390

Graf R, Schiesser M, Scheele GA, Marquardt K, Frick TW, Ammann RW, Bimmler D (2001) A family of 16-kDa pancreatic secretory stress proteins form highly organized fibrillar structures upon tryptic activation. J Biol Chem 276:21028-21038

Graf R, Schiesser M, Lussi A, Went P, Scheele GA, Bimmler D (2002) Coordinate regulation of secretory stress proteins (PSP/ reg, PAP I, PAP II, and PAP III) in the rat exocrine pancreas during experimental acute pancreatitis. J Surg Res 105:136-144

Graf R, Schiesser M, Reding T, Appenzeller P, Sun LK, Fortunato F, Perren A, Bimmler D (2006) Exocrine meets endocrine: pancreatic stone protein and regenerating protein-two sides of the same coin. J Surg Res 133:113-120 
He SQ, Yao JR, Zhang FX, Wang Q, Bao L, Zhang X (2010) Inflammation and nerve injury induce expression of pancreatitisassociated protein-II in primary sensory neurons. Mol Pain 6:23-34

Jones SA, Richards PJ, Scheller J, Rose-John S (2005) IL-6 transsignaling: the in vivo consequences. $\mathrm{J}$ Interferon Cytokine Res 25:241-253

Kawahara S, Konishi H, Morino M, Ohata K, Kiyama H (2011) Pancreatitis-associated protein-I and pancreatitis-associated protein-III expression in a rat model of kainic acid-induced seizure. Neuroscience 175:273-280

Kunz D, Walker G, Bedoucha M, Certa U, März-Weiss P, Dimitriades-Schmutz B, Otten U (2009) Expression profiling and ingenuity biological function analyses of interleukin-6- versus nerve growth factor-stimulated PC12 cells. BMC Genomics 10:90-98

Li L, Bachem MG, Zhou S, Sun Z, Chen J, Siech M, Bimmler D, Graf R (2009) Pancreatitis-associated protein inhibits human pancreatic stellate cell MMP-1 and -2, TIMP-1 and -2 secretion and RECK expression. Pancreatology 9:99-110

Livesey FJ, O’Brien JA, Li M, Smith AG, Murphy LJ, Hunt SP (1997) A Schwann cell mitogen accompanying regeneration of motor neurons. Nature 390:614-618

Maas AIR, Stocchetti N, Bullock R (2008) Moderate and severe traumatic brain injury in adults. Lancet Neurol 7:728-741

März P, Herget Th, Lang E, Otten U, Rose-John S (1998) Activation of gp130 by IL-6/soluble IL-6 receptor induces neuronal differentiation. Eur J Neurosci 10:2765-2773

März P, Otten U, Rose-John S (1999) Neuronal activities of IL-6 type cytokines often depend on soluble cytokine receptors. Eur J Neurosci 11:2995-3004

Mazzeo AT, Beat A, Singh A, Bullock MR (2009) The role of mitochondrial transition pore, and its modulation, in traumatic brain injury and delayed neurodegeneration after TBI. Exp Neurol 218:363-370

Namikawa K, Fukushima M, Murakami K, Suzuki A, Takasawa S, Okamoto H, Kiyama H (2005) Expression of Reg/PAP family members during motor nerve regeneration in rat. Biochem Biophys Res Commun 332:126-134

Namikawa K, Okamoto T, Suzuki A, Konishi H, Kiyama H (2006) Pancreatitis-associated protein-III is a novel macrophage chemoattractant implicated in nerve regeneration. J Neurosci 26: 7460-7467

Nishimune H, Vasseur S, Wiese S, Birling MC, Holtmann B, Sendtner M, Iovanna JL, Henderson CE (2000) Reg-2 is a motoneuron neurotrophic factor and a signalling intermediate in the CNTF survival pathway. Nat Cell Biol 2:906-914
Peng YP, Qiu YH, Lu JH, Wang JJ (2005) Interleukin-6 protects cultured cerebellar granule neurons against glutamate-induced neurotoxicity. Neurosci Lett 374:192-196

Penkowa M, Camats J, Hadberg H, Quintana A, Rojas S, Giralt M, Molinero A, Campbell IL, Hidalgo J (2003a) Astrocyte-targeted expression of interleukin- 6 protects the central nervous system during neuroglial degeneration induced by 6 -aminonicotinamide. J Neurosci Res 73:481-496

Penkowa M, Giralt M, Lago N, Camats J, Carrasco J, Hernández J, Molinero A, Campbell IL, Hidalgo J (2003b) Astrocyte-targeted expression of IL- 6 protects the CNS against a focal brain injury. Exp Neurol 181:130-148

Pizzi M, Sarnico I, Boroni F, Benarese M, Dreano M, Garotta G, Valerio A, Spano P (2004) Prevention of neuron and oligodendrocyte degeneration by interleukin-6 (IL-6) and IL-6 receptor/ IL-6 fusion protein in organotypic hippocampal slices. Mol Cell Neurosci 25:301-311

Rose-John S, Waetzig GH, Scheller J, Grötzinger J, Seegert D (2007) The IL-6/s-IL-6R complex as a novel target for therapeutic approaches. Expert Opin Ther Targtes 11:613-624

Schiesser M, Bimmler D, Frick TW, Graf R (2001) Conformational changes of pancreatitis-associated protein (PAP) activated by trypsin lead to insoluble protein aggregates. Pancreas 22: $186-192$

Selkoe DJ (2003) Folding proteins in fatal ways. Nature 426:900-904

Soto C (2003) Unfolding the role of protein misfolding in neurodegenerative diseases. Nat Rev Neurosci 4:49-60

Sun Y, Marz P, Otten U, Ge J, Rose-John S (2002) The effect of gp130 stimulation on glutamate-induced excitotoxicity in primary hippocampal neurons. Biochem Biophys Res Commun 295: 532-539

Valerio A, Ferrario M, Dreano M, Garotta G, Spano P, Pizzi M (2002) Soluble interleukin-6 (IL-6) receptor/IL-6 fusion protein enhances in vitro differentiation of purified rat oligodendroglial lineage cells. Mol Cell Neurosci 21:602-615

Yamashita T, Sawamoto K, Suzuki S, Suzuki N, Adachi K, Kawase T, Mihara M, Ohsugi Y, Abe K, Okano H (2005) Blockade of interleukin-6 signaling aggravates ischemic cerebral damage in mice: possible involvement of STAT3 activation in the protection of neurons. J Neurochem 94:459-468

Zhang YW, Ding LS, Lai MD (2003) Reg gene family and human diseases. World J Gastroenterol 9:2635-2641

Zhang PL, Izrael M, Ainbinder E, Ben-Simchon L, Chebath J, Revel M (2006) Increased myelinating capacity of embryonic stem cell derived oligodendrocyte precursors after treatment by interleukin-6/soluble interleukin-6 receptor fusion protein. Mol Cell Neurosci 31:387-398 